\title{
Seroprevalence, Genotyping, and Monitoring of Hepatitis C Viral Loads in Patients on Antivirals in Burkina Faso
}

\author{
Edwige T. Yelemkoure ${ }^{a, b}$ Albert T. Yonli ${ }^{a, b}$ Hermann K. Sombie ${ }^{a, b}$ \\ Issoufou Tao ${ }^{b, c}$ Abdou Azaque Zouréa, d Abdoul Karim Ouattara ${ }^{b, e}$ \\ Abel P. Sorgho ${ }^{a, b}$ Arsène W. Zongo ${ }^{a, b}$ Moctar T.A. Zeba ${ }^{a, b}$ \\ Isabelle T. Kiendrebeogo ${ }^{a, b}$ Prosper Bado ${ }^{a, b}$ Madeleine K. Kabréa, \\ Théodora M. Zohoncon ${ }^{a, f}$ Florencia W. Djigma ${ }^{a, b}$ Dorcas Obiri-Yeboah ${ }^{b, g}$ \\ Jacques Simpore ${ }^{a, b}, f$
}

\begin{abstract}
aLaboratory of Molecular Biology and Genetics (LABIOGENE), University Joseph Ki-Zerbo, Ouagadougou, Burkina Faso; bPietro Annigoni Biomolecular Research Centre (CERBA), Ouagadougou, Burkina Faso; Institute of Sciences,

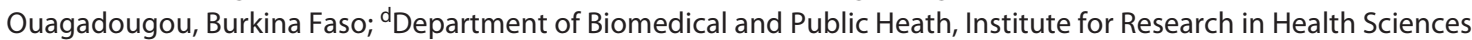
(IRSS/CNRST), Ouagadougou, Burkina Faso; eUniversity Center of Manga, Norbert ZONGO University, Koudougou, Burkina Faso; fUniversity Saint Thomas d'Aquin, Faculty of Medicine, Ouagadougou, Burkina Faso; 9 Department of Microbiology and Immunology, University of Cape Coast, School of Medical Sciences, Cape Coast, Ghana
\end{abstract}

\section{Keywords}

Hepatitis C virus · Genotype · Viral load · Pan-genotypic drugs · Burkina Faso

\begin{abstract}
Introduction: Hepatitis $\mathrm{C}$ virus (HCV) infection remains a major public health problem worldwide. In Burkina Faso, nearly 720,000 people are living with HCV, and each year about 900 people die from complications of cirrhosis or hepatocellular carcinoma. This study was planned to determine the HCV seroprevalence, characterize circulating genotypes, and monitor HCV viral loads in patients under treatment with antivirals. Methods: A total of 4,124 individuals and 167 patients in the pre-therapy program were recruited. The "SD Bioline HCV" kit was used for rapid screening of anti-HCV an-
\end{abstract}

tibodies. Viral load and genotyping were performed in 167 HCV patients on antivirals using the "Iontek HCV Quant" and "lontek genotyping" kits. Results: Prevalence of HCV was $1.65 \%(68 / 4,124)$, and the median viral load of participants was $5.37 \log 10 / \mathrm{mL}(1.32-7.67 \log 10 / \mathrm{mL})$. Genotype 2 was predominant with a frequency of $86.23 \%$ (144/167) and appeared to be more active with higher viral load compared to $13.77 \%$ (23/167) for genotype 1 ( $p<0.001)$. After 24 weeks of pan-genotypic direct-acting antivirals, such as sofosbuvir/ daclatasvir and sofosbuvir/velpatasvir, the viral loads of all patients became undetectable. Conclusion: The responses to antivirals by the circulating genotypes indicate that the results are very satisfactory. Therefore, the prevalence of $\mathrm{HCV}$ in the population can be reduced through identification of cases and treatment.

(c) 2021 The Author(s). Published by S. Karger AG, Basel
C 2021 The Author(s).

Published by S. Karger AG, Basel

This is an Open Access article licensed under the Creative Commons Attribution-NonCommercial-4.0 International License (CC BY-NC) (http://www.karger.com/Services/OpenAccessLicense), applicable to the online version of the article only. Usage and distribution for commercial purposes requires written permission. 


\section{Introduction}

Hepatitis $\mathrm{C}$ virus (HCV) infection remains a major public health problem worldwide. It is one of the causes of high morbidity and mortality in the working population with significant socioeconomic consequences [1]. Several studies have shown that chronic infection of HCV is the leading cause of cirrhosis and hepatocellular carcinoma worldwide [2-4]. According to the WHO, close to 71 million people worldwide are chronic carriers of $\mathrm{HCV}$ with 399,000 deaths each year from complications such as cirrhosis and hepatocellular carcinoma [5].

Africa is one of the continents with a high prevalence rate with 19 million people chronically infected by HCV [6]. In Burkina Faso, nearly 720,000 people are living with HCV [4]. The number of deaths due to complications such as cirrhosis and primary liver cancer is about 900 per year in Burkina Faso [7]. The Fifth General Census of Population and Housing (fifth ERGPH) of Burkina Faso, which took place at the end of 2019, gives a total population of $20,487,979$ composed of $9,894,028$ or $48.3 \%$ men and $10,593,951$ or $51.7 \%$ women [8]. In Burkina Faso, as in other African countries, the available data show that $\mathrm{HCV}$ is endemic with various prevalences. Antiviral drugs can cure $95 \%$ of $\mathrm{HCV}$-infected people, but access to diagnosis and treatment remains limited in resource-limited countries including Burkina Faso [9]. Rapid diagnostic tests for anti-HCV antibodies show high prevalences among blood donors with levels of 3.9\% [10-12] and low rates in the general population in Burkina Faso [13].

The HCV has several genotypes and subtypes, including 7 genotypes from 1 to 7 and 84 subtypes $[14,15]$. In Burkina Faso, the molecular epidemiology of $\mathrm{HCV}$ is poorly documented, and most of the existing data relate to seroprevalence based solely on $\mathrm{HCV}$ antibody testing of blood donors and pregnant women [16-18]. Determining $\mathrm{HCV}$ genotypes is very important for identifying infected patients who are at increased risk of disease progression in order to optimize treatment and identify possible mutations [19]. To date, hepatitis $C$ has no vaccine, and therefore treatment is essential. In developing countries, for the treatment of $\mathrm{HCV}$, interferon is commonly used, with all its several side effects such as fever, headache, fatigue, arthralgia, and myalgias. Direct-acting antivirals (DAAs) are molecules that treat all genotypes of the HCV with document cure rate above 95\% [20, 21]. In developed countries, pan-genotypic DAAs have shown their effectiveness in the treatment of HCV. However, the efficacy of these pan-genotypic DAAs has not yet been demonstrated in patients from Burkina Faso with chronic hepatitis $\mathrm{C}$.
In 2017, Burkina Faso developed a strategic plan to fight against viral hepatitis $C$ that did not consider specific protocols for the treatment of viral hepatitis $\mathrm{C}$. The treatment is allowed for free choice to clinicians and patients [22]. In 2019, the standards and protocols for the management of viral hepatitis were established with the introduction of pan-genotypic molecules at subsidized cost. The diagnosis, which is the first means of fighting against HCV infection, remains at the patient's expense, as well as the follow-up tests before and during treatment. Among the molecules used in the treatment against $\mathrm{HCV}$, first-line combination of sofosbuvir/velpatasvir is used in cirrhotic and noncirrhotic patients without addition of ribavirin, and for second line, the combination sofosbuvir/daclatasvir. In case of first-line treatment failure, the combinations of sofosbuvir/velpatasvir/voxilaprevir as the first option and glecaprevir/pibrentasvir as the second option are recommended [23]. The aim of this research work was to evaluate the prevalence of hepatitis $C$ in Burkina Faso, to characterize the circulating genotypes, and finally to follow the evolution of viremia in HCVpositive patients under pan-genotypic DAA treatment.

\section{Materials and Methods}

\section{Study Design and Population}

A cross-sectional descriptive study took place from June 2016 to June 2019 at the Pietro Annigoni Centre for Biomolecular Research (CERBA) and the Laboratory of Molecular Biology and Genetics (LABIOGENE) of the Joseph KI-ZERBO University in Ouagadougou, Burkina Faso. The study included 4,124 individuals who came for HCV antibody screening on their own initiative or following medical instruction. In addition, $99 \mathrm{HCV}$-positive patients receiving care at CERBA/LABIOGENE were recruited. Viral load and genotyping were performed in all the HCV identified positives cases.

\section{Laboratory Methods}

Eight milliliters of venous blood was collected from the participants for the various serological and molecular tests. The SD Bioline HCV kit in a multi-cassette box/100 tests (Borahagal-Ro, Giheung-Gu, Yongin-Si, Gyeonggi-Da, South Korea) was used for the rapid diagnosis of $\mathrm{HCV}$ by qualitative detection of $\mathrm{HCV}$-specific antibodies in serum or plasma.

\section{Extraction of HCV RNA}

HCV RNA was extracted using the kit "ABIOpure ${ }^{\mathrm{TM}}$ Viral DNA/RNA Extraction” (Alliance Bio, Bothell, WA98021, USA) following the recommendations or instructions of the manufacturer. Viral load and HCV genotyping were performed, respectively, using the kits "Iontek HCV Quant (Istanbul, Turkey)" and "Iontek genotyping Real Time PCR (Istanbul, Turkey) on the ABI 7500 Fast Real-Time PCR System" (Applied Bio systems, Waltham, MA, USA) following the protocol provided by the manufacturer. 
Table 1. Population serological status according to the sociodemographic characteristics of the 4,124 subjects of the study

\begin{tabular}{|c|c|c|c|c|}
\hline Variables & $N=4,124$ & $\begin{array}{l}\text { HCV positive } \\
(n=68)\end{array}$ & $\begin{array}{l}\text { Prevalence } \\
\text { of HCV }\end{array}$ & $p$ value \\
\hline \multicolumn{5}{|l|}{ Women, years } \\
\hline$<20$ & 403 & 2 & 0.50 & \multirow{5}{*}{$<0.001$} \\
\hline $20-35$ & 1,353 & 12 & 0.89 & \\
\hline $35-50$ & 537 & 8 & 1.49 & \\
\hline$>50$ & 181 & 13 & 7.18 & \\
\hline Subtotal & 2,474 & 35 & 1.41 & \\
\hline \multicolumn{5}{|l|}{ Men, years } \\
\hline$<20$ & 299 & 2 & 0.67 & \multirow{4}{*}{$<0.001$} \\
\hline $20-35$ & 732 & 11 & 1.50 & \\
\hline $35-50$ & 454 & 8 & 1.76 & \\
\hline$>50$ & 165 & 12 & 7.27 & \\
\hline Subtotal & 1,650 & 33 & 2 & \\
\hline \multicolumn{5}{|l|}{ General population, years } \\
\hline$<20$ & 702 & 4 & 0.57 & \multirow{5}{*}{$<0.001$} \\
\hline $20-35$ & 2085 & 23 & 1.10 & \\
\hline $35-50$ & 991 & 16 & 1.61 & \\
\hline$>50$ & 346 & 25 & 7.23 & \\
\hline Total & 4,124 & 68 & 1.65 & \\
\hline \multicolumn{5}{|l|}{ Profession } \\
\hline Civil servants & 1,284 & 22 & 1.71 & \multirow{5}{*}{0.999} \\
\hline Pupils/students & 420 & 7 & 1.67 & \\
\hline Informal sector & 766 & 12 & 1.57 & \\
\hline Housewives/cultivators & 1,284 & 21 & 1.64 & \\
\hline Retired & 370 & 6 & 1.62 & \\
\hline \multicolumn{5}{|l|}{ Marital status } \\
\hline Married & 3,334 & 55 & 1.65 & \multirow{3}{*}{0.921} \\
\hline Singles & 642 & 10 & 1.56 & \\
\hline Widows/widowers & 148 & 3 & 2.02 & \\
\hline \multicolumn{5}{|l|}{ Level of education } \\
\hline No formal education & 1,235 & 21 & 1.7 & \multirow{4}{*}{0.997} \\
\hline Primary & 469 & 8 & 1.7 & \\
\hline Secondary & 1,432 & 23 & 1.6 & \\
\hline Post-secondary & 988 & 16 & 1.6 & \\
\hline \multicolumn{5}{|l|}{ Residence } \\
\hline Urban & 2,889 & 30 & 1.04 & \multirow{2}{*}{$<0.001$} \\
\hline Rural & 1,235 & 38 & 3.07 & \\
\hline
\end{tabular}

HCV, hepatitis C virus.
Statistical Analysis

The results of this study were recorded in Excel 2016 and analyzed using SPSS version 17.0 and Epi info version 7.0. The $\chi^{2}$ test was used for proportion comparisons, and the difference was considered significant for $p<0.05$.

\section{Results}

\section{Prevalence of $\mathrm{HCV}$}

Table 1 shows the general characteristics of the 4,124 subjects included in the study. Figure 1 shows the distribution of HCV prevalence according to patient's residence across Burkina Faso.

Seroprevalence, Genotyping, and Monitoring of Hepatitis C Viral Loads
The age range of these individuals was between 18 and 75 years with an average of $44 \pm 0.19$ years. HCV RNA was detected in 68 subjects, giving a prevalence of $1.65 \%$ $(68 / 4,124)$. The age group most infected with HCV was over 50 years of age with a frequency of $7.23 \%$. Female patients of the study population had a low HCV prevalence of $1.41 \%$ compared to males with an HCV prevalence of $2 \%$.

According to the sociodemographic characteristics, there was no statistically significant difference between HCV antibody prevalence by occupation $(p=0.999)$, marital status ( $p=0.921)$, and education level $(p=0.997)$. However, there was a statistically significant difference 


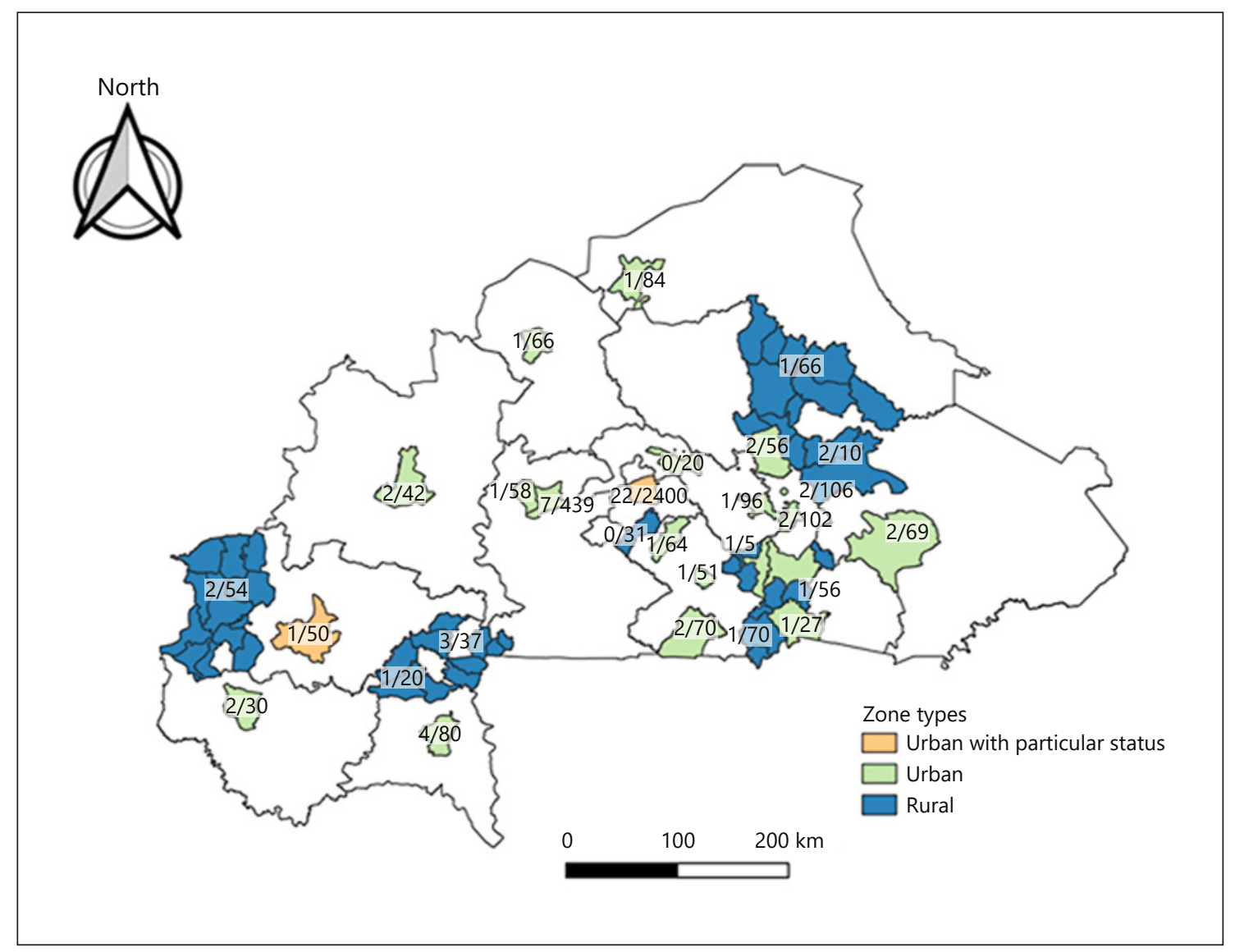

Fig. 1. HCV-positive/screening subjects according to the different zones of Burkina Faso. HCV, hepatitis C virus.

between urban and rural HCV antibody prevalence $(p<$ 0.001) (Table 1).

\section{Viral Load Assessment and Genotyping}

Table 2 shows the distribution of viral load according to sex and HCV genotype. The total HCV-positive cases in this study was 167 patients made up of the 68 identified through the general screening and the 99 receiving care at CERBA. These 167 patients completed the HCV viral load testing before and at the end of treatment. The results showed that before treatment $>88.62 \%$ of patients had a viral load $>1000 \mathrm{IU} / \mathrm{mL}$ with a median of $5.39 \log 10$ $(1.32-7.74 \log 10 / \mathrm{mL})$ for men and $5.26 \log 10(1.32-7.40$ $\log 10 / \mathrm{mL})$ for women $(p<0.001)$.

One hundred and sixty-seven HCV-positive patients including 106 men (63.47\%) and 61 women (36.53\%) with detectable viral load (before treatment) were genotyped. In this study, only 2 genotypes were found: genotypes 1 and 2 . The genotyping results showed that genotype 2 was the most predominant with a frequency of
$86.23 \%$ versus $13.77 \%$ of genotype 1 ( $p<0.001)$. Similarly, the median viral load was higher in subjects with genotype 2 at $5.63 \log 10(1.75-7.67 \log 10 / \mathrm{mL})$ compared to those with genotype 1 at $4.93 \log 10(3.80-6.48 \log 10 /$ $\mathrm{mL}$ ), and the difference was statistically significant $(p<$ 0.001) (Table 2).

\section{Medical Treatment according to HCV Genotype and Viral Load}

One hundred and sixty-seven participants with known genotypes, namely, genotype 1 and genotype 2 , were put under antiviral therapy. Depending on the molecule used and the level of viral load before the start of treatment (W0), the evolution of viral load was evaluated at 12 weeks (W12) and 24 weeks (W24) after the start of treatment (W0). The median viral load during the different periods and the number of patients $(n=167)$ are shown in Table 3.

After 12 and 24 weeks of treatment, respectively, $91.02 \%$ and $100 \%$ of patients had undetectable viral loads. 
Table 2. Distribution of HCV viral load before treatment by sex and genotype for 167 subjects of the study

\begin{tabular}{|c|c|c|c|c|c|c|c|c|c|}
\hline & $N$ & genotype 1 & genotype 2 & $p$ value & $<50$ & $50-1,000$ & $>1,000$ & $\begin{array}{l}\text { VL* median, } \\
\log 10 / \mathrm{mL}\end{array}$ & $p$ value \\
\hline \multicolumn{10}{|c|}{ Gender, $n(\%)$} \\
\hline Men & $106(63.47)$ & $15(14.15)$ & $91(85.85)$ & \multirow{2}{*}{$<0.001$} & $7(6.6)$ & $4(3.8)$ & 95 (89.7) & $5.39(1.32-7.74)$ & \multirow{2}{*}{$<0.001$} \\
\hline Women & $61(36.53)$ & $8(13.11)$ & $53(86.89)$ & & $2(3.3)$ & $6(9.8)$ & $53(86.9)$ & $5.26(1.32-7.40)$ & \\
\hline 2 & $144(86.23)$ & - & - & - & $8(5.6)$ & $8(5.6)$ & $128(88.8)$ & $5.63(1.75-7.67)$ & \multirow{2}{*}{$<0.001$} \\
\hline Total & 167 & 23 & 144 & & 9 & 10 & 148 & & \\
\hline
\end{tabular}

HCV, hepatitis C virus. * VL, viral load.

Table 3. Median viral load results of patients presented according to the regimen and at weeks 0,12 , and 24 on treatment

\begin{tabular}{|c|c|c|c|c|c|c|}
\hline \multirow[t]{3}{*}{ Treatment regimen } & \multicolumn{6}{|c|}{ Viral load results, UI/mL } \\
\hline & \multicolumn{3}{|l|}{ genotype 1} & \multicolumn{3}{|l|}{ genotype 2} \\
\hline & Wo & W12 & W24 & wo & W12 & W24 \\
\hline Daclatasvir + ribavirin $(n)$ & $61.945(8)$ & Undetectable & Undetectable & \multicolumn{3}{|c|}{ Molecule not used for this genotype } \\
\hline Interferon ( $n)$ & \multicolumn{3}{|c|}{ Molecule not used for this genotype } & $1,387.331(10)$ & Undetectable & Undetectable \\
\hline Ledipasvir + sofosbuvir $(n)$ & $1,444.201(10)$ & Undetectable & Undetectable & $1,141.602(15)$ & $512.340(10)$ & Undetectable \\
\hline Sofosbuvir + daclatasvir ( $n)$ & \multicolumn{3}{|c|}{ Molecule not used for this genotype } & $719.436(5)$ & Undetectable & Undetectable \\
\hline Sofosbuvir + ribavirin $(n)$ & \multicolumn{3}{|c|}{ Molecule not used for this genotype } & $1,124.987(46)$ & $12(5)$ & Undetectable \\
\hline Sofosbuvir + velpatasvir $(n)$ & $8.011(5)$ & Undetectable & Undetectable & $2,163.767(68)$ & Undetectable & Undetectable \\
\hline
\end{tabular}

W0, median viral load before the start of treatment; W12, median viral load 12 weeks after treatment; W24, median viral load 24 weeks after treatment; $n$, number of individuals.

DAAs such as sofosbuvir/daclatasvir and sofosbuvir/velpatasvir induced undetectable viral load after only 12 weeks of treatment.

\section{Discussion}

In this research, the prevalence of anti-HCV antibody was $1.65 \%(68 / 4,124)$. However, it is important to specify that this rate varied according to the sociodemographic characteristics of our study population: from $1.57 \%$ among individuals in the informal sector to $3.07 \%$ among rural dwellers, singles (1.5\%), civil servants $(1.71 \%)$, and widows/widowers (2.02\%). The high prevalence in rural areas $(3.07 \%)$ compared to urban areas (1.04\%), with $p<$ 0.001 , could be explained by the fact that most of the patients were from the southwestern region of Burkina
Faso, which is the area with a high prevalence of viral hepatitis: $9.1 \%$ for HBV and 3.6\% for HCV [6].

Our study population was between 18 and 75 years of age ( $44 \pm 0.19$ years). The age range most represented was between 20 and 35 years of age, or $49.42 \%$ of the population. The most infected age group was over 50 years of age with a prevalence of HCV infection of $7.23 \%$ versus $1.65 \%$ in the overall population. This high prevalence in the over-50 age group could be explained by risk behaviors. The overall prevalence of the study of $1.65 \%$ is similar to those found by other studies $[11,17,24]$ among blood donors in Ouagadougou: $1.8 \%, 2.1 \%$, and $2 \%$, respectively. However, the prevalence of this study is lower than the $3.6 \%$ found by Meda et al. [6] in the general population, the $6.5-8.7 \%$ among blood donors by Nagalo et al. [10], and the $5.4 \%$ among pregnant women in Ouagadougou by Simporé et al. [13]. This could be explained by in- 
creased sensitization, screening, and treatment over the years through World Hepatitis Days. Likewise, the prevalence in this study is higher than the $1 \%$ found by Tao et al. [25] in the general population.

In our study, women were the least affected with a prevalence of $1.41 \%$ compared to $2 \%$ for men. Our results corroborate those of Meda et al. [6] which showed that HCV seroprevalence was higher in men (3.9\%) compared to women (3.2\%) and could be attributed to health-seeking behaviors of females compared with males.

After diagnosis, we performed viral load testing of all $\mathrm{HCV}$ antibody-positive individuals and determined $\mathrm{HCV}$ genotypes in 167 individuals. In both males and females, $80 \%$ had a viral load $>1000 \mathrm{IU} / \mathrm{mL}$, with a significantly higher median in males (5.39 $\log 10$ [1.32-7.74 $\log 10 / \mathrm{mL}])$ than in females $(5.26 \log 10$ [1.32-7.40 $\log 10 /$ $\mathrm{mL}]$ ). Several studies have already shown that high viral load is a risk factor for the progression of hepatitis $\mathrm{C}$ to cirrhosis and hepatocellular carcinoma [26, 27]. Our results would suggest that men were at increased risk of developing liver cancer or cirrhosis following chronic $\mathrm{HCV}$ infection. Our results corroborate those found by El-Serag and Rudolph [28] which showed that advanced age and male sex are risk factors for the development of hepatocellular carcinoma. It was also demonstrated by White [29] that elevated testosterone levels were linked to advanced liver fibrosis in men with chronic hepatitis $\mathrm{C}$ and HCC in hepatitis B carriers.

Genotyping showed that HCV genotype 2 was the most common in our study population. Besides genotype 1 and genotype 2, no other genotypes were detected in our study population, suggesting that these genotypes are those commonly encountered in Burkina Faso. Our results corroborate those of Assih et al. [30] who found that $\mathrm{HCV}$ genotypes 1 and 2 accounted for $96.4 \%$ of HCV infections in West African countries. Genotype 2 (2a) is predominantly represented in Benin, Burkina Faso, Ghana, Guinea Bissau, and Mali while genotype 1 is predominant in Côte d'Ivoire, Senegal, and Nigeria [31]. However, there was no correlation between the genotype and the geographical location of the subjects in our study.

Among the molecules used, we have interferon- $\alpha$ (IFN- $\alpha$ ) which is an antiviral molecule produced naturally by immune cells allowing a decrease in viral replication in a nonspecific manner by activating natural killer cells and CD8 T lymphocytes [32]. Sofosbuvir is an NS5B polymerase inhibitor that acts by blocking the replication of the virus [33]. For genotypes 1 and 2, and after 12 weeks of treatment, $88.62 \%$ of patients had undetectable viremia and $100 \%$ had an undetectable viral load at 24 weeks of treatment regardless of the molecule used. For effective patient follow-up, quantification of viral RNA would be the most appropriate means [20]. In addition, pan-genotypic DAA drugs, such as sofosbuvir/daclatasvir and sofosbuvir/velpatasvir, would be more effective against $\mathrm{HCV}$ infection, hence the need to subsidize their cost to facilitate their prescription by Burkinabe clinicians.

In our study, the following molecules (ribavirin + daclatasvir, sofosbuvir + ledipasvir, and sofosbuvir + velpatasvir) were used in the treatment of genotype 1. For genotype 2, interferon, sofosbuvir + daclatasvir, sofosbuvir + ledipasvir, sofosbuvir + ribavirin, and sofosbuvir + velpatasvir were used. The pan-genotypic molecules (sofosbuvir + daclatasvir and sofosbuvir + velpatasvir) resulted in an undetectable viral load after 12 weeks of treatment regardless of the genotype (1 and 2). Also, daclatasvir + ribavirin for genotype 1 and interferon for genotype 2 gave an undetectable viral load after 12 weeks of treatment, while the other molecules like sofosbuvir + ledipasvir and sofosbuvir + ribavirin gave detectable viral loads after 12 weeks of treatment for genotype 2 . These results corroborate those of Sakr et al. [34] who showed that pangenotypic molecules were very effective in the treatment of HCV infection with a success rate of $95-100 \%$ regardless of the genotype. The detectable viral load after 12 weeks of treatment with genotype 2 could be explained by the fact that these patients had a very high viral load prior to treatment, and sofosbuvir + ledipasvir and sofosbuvir + ribavirin were better indicated for treatment of genotype 1 . Studies have shown that genomic RNA has different lengths among HCV genotypes, and these differences may affect some properties of the virus, such as pathogenicity, clinical manifestations, response to treatment, and inability to produce $\mathrm{HCV}$ vaccines $[35,36]$.

According to Zuberi et al. [37], genotypes 2 and 3 have poor response to treatment compared to genotypes 1 and 4 , which respond well to IFN plus ribavirin combination therapy. In general, in genotypes 2 and 3 , the response to treatment is poor compared to genotypes 1 and 4; therefore, the treatment period is longer [38, 39].

Also, in addition to the genotype, several important factors, such as interleukin 28B (IL28B) polymorphism, cirrhosis status, coinfection with other infectious diseases [40], and drug susceptibility testing of HCV strains, need to be considered for effective treatment of $\mathrm{HCV}$ infections [41-43]. We found a difference in treatment response between genotype 1 patients with undetectable viral load after 12 weeks and genotype 2 patients with detectable viral load after 12 weeks with the sofosbuvir/ ledipasvir combination. 
Our results show that this treatment gives a rapid response with genotype 1 and a slower response with genotype 2 . These results could be explained by the fact that genotype 1 is more sensitive to sofosbuvir/ledipasvir compared to genotype 2 thus prolonging the duration of treatment to 24 weeks to achieve an undetectable viral load [44]. This result would not be related to the initial viral load because all patients of genotype 1 and 2 had a similar high viral load in this study. However, other authors have shown that host factors, such as the presence of cirrhosis, social criteria, adherence to treatment, and drug interactions, influence the sustained viral response, particularly in older patients [44]. In addition, viral factors, such as viral load, genotype, and presence of baseline resistance, affect the response rate [45].

In Burkina Faso, screening for hepatitis is not routine, except among blood donors and some HIV-infected individuals. HIV-induced immunosuppression affects immunity to $\mathrm{HCV}$, increasing HCV plasma viral load, but these and other risk factors for HCV acquisition were not the focus of this study. Although Burkina Faso complies with blood safety standards, residual risks associated with transfusion exist, but HBV/HCV/HIV coinfections were not studied in this research. This represents a limitation of our study because these infections influence the natural history of these viruses, the evolution of these diseases, and the response to treatment [46].

With the arrival of DAAs in 2019, Burkina Faso has adopted a protocol for the management of $\mathrm{HCV}$, which allows for the effective fight against HCV from diagnosis to treatment. However, there is a lack of awareness, and the subsidized treatment is still not affordable to the majority of patients. Screening and the various other followup laboratory tests for screen positives are not subsidized, and this impacts care and requires attention. Routine screening for $\mathrm{HCV}$ for pregnant women should also be considered, and the national guidelines must be revised periodically to respond to new strategies in the fight against viral hepatitis.

\section{Conclusion}

This study found HCV prevalence of $1.65 \%$ and demonstrated that genotype 2 remains the most prevalent in Burkina Faso. DAAs were also shown to be effective in the treatment of HCV-infected persons in Burkina Faso. However, the costs of DAAs are very expensive for most African countries. Nevertheless, it is necessary to continue to follow patients who have recovered from the infection but whose liver damage, such as severe fibrosis, significantly increases their risk of cancer. In order to detect the risks of this liver tumor at an early stage, a large-scale epigenetic study on cancerous liver tissue would be necessary in the West African subregion, including in Burkina Faso.

\section{Acknowledgments}

The authors would like to thank the Laboratory of Molecular Biology and Genetics (LABIOGENE) UFR/SVT, University Joseph KI-ZERBO, Burkina Faso, and the Biomolecular Research Centre Pietro Annigoni of Ouagadougou (CERBA) for technical and financial support.

\section{Statement of Ethics}

The Ethics Committee for Health Research (CERS) of Burkina Faso has approved this study (Deliberation No. 2013-7-065 of July 11, 2013). All participants have given their free and written informed consent to participate in the study. Anonymity and confidentiality with respect to the information collected was scrupulously respected.

\section{Conflict of Interest Statement}

The authors declare that they have no competing interests.

\section{Funding Sources}

This study was supported by the Pietro Annigoni Biomolecular Research Centre (CERBA), 01 BP 364 Ouagadougou 01, Burkina Faso, fellowship.

\section{Author Contributions}

E.T.Y., F.W.D., T.M.Z., A.A.Z., and J.S. contributed to study concept and design; E.T.Y., H.S., A.S., A.Y., P.B., and M.K. contributed to sample collection and processing; A.K.O., I.T.K., A.Z., and E.T.Y. contributed to statistical analysis and interpretation of data; E.T.Y., F.W.D., A.A.Z., M.Z., M.K., and D.O-Y. contributed to drafting of the manuscript; I.K., A.K.O., T.M.Z., A.A.Z., M.Z., F.W.D., I.T., and J.S. contributed to critical revision of the manuscript for important intellectual content; A.K.O., I.T., and J.S. contributed to administrative, technical, and material support; J.S., F.W.D., and D.O-Y. contributed to study supervision.

\section{Data Availability Statement}

Data sharing is not applicable to this article. 


\section{References}

1 WHO. Guidelines for the Screening Care and Treatment of Persons with Chronic Hepatitis C Infection: Updated Version. World Health Organisation; 2016. Available from: https:// pubmed.ncbi.nlm.nih.gov/27227200/. consulted in 2021 Apr.

2 Di Bisceglie AM, Bonkovsky HL, Chopra S, Flamm S, Reddy RK, Grace N, et al. Iron reduction as an adjuvant to interferon therapy in patients with chronic hepatitis $\mathrm{C}$ who have previously not responded to interferon: a multicenter, prospective, randomized, controlled trial. Hepatology. 2000 Jul;32(1):135-8.

3 Bihl F, Pache I, Hess J, Moradpour D. Le point sur le traitement de l'hépatite $\mathrm{C}$ chronique [an update on the management of chronic hepatitis C]. Rev Med Suisse. 2010 Jan 27;6(233): 174, 176-9.

4 WHO. Guidelines for the care and treatment of persons diagnosed with chronic hepatitis C virus infection. World Health Organisation; 2018. Available from: https://apps.who.int/ iris/bitstream/handle/10665/273174/ 9789241550345-eng.pdf. consulted in 2021 Apr.

5 WHO. Global hepatitis report. World Health Organisation; 2017. Available from: https:// apps.who.int/iris/bitstream/handle/10665/ 273174/9789241550345-eng.pdf consulted in 2021 Apr.

6 Meda N, Tuaillon E, Kania D, Tiendrebeogo A, Pisoni A, Zida S, et al. Hepatitis B and C virus seroprevalence, Burkina Faso: a crosssectional study. Bull World Health Organ. 2018 Nov 1;96(11):750-9.

7 Ministère. Normes et protocoles de prise en charge des hépatites vIrales au Burkina Faso. Burkina Faso: Ministère de la Santé; 2019. Available from: https://scge-cm.com/download/Normes et protocoles de Prise en charge HV au BF Vf 2019.pdf consulted in 2021 Apr.

8 National Institute of Statistics and Demography. Fifth Burkina Faso Demographic and Health Survey. Burkina Faso: National Institute of Statistics and Demography; 2021. Available from: http://ghdx.healthdata.org/ organizations/national-institute-statisticsand-demography-burkina-faso consulted in $2021 \mathrm{Apr}$

9 Asselah T, Boyer N, Saadoun D, MartinotPeignoux M, Marcellin P. Direct-acting antivirals for the treatment of hepatitis $C$ virus infection: optimizing current IFN-free treatment and future perspectives. Liver Int. 2016 Jan;36(Suppl 1):47-57.

10 Nagalo MB, Sanou M, Bisseye C, Kaboré MI, Nebie YK, Kienou K, et al. Seroprevalence of human immunodeficiency virus, hepatitis B and $\mathrm{C}$ viruses and syphilis among blood donors in Koudougou (Burkina Faso) in 2009. Blood Transfus. 2011 Oct;9(4):419-24.
11 Zeba MT, Karou SD, Sagna T, Djigma F, Bisseye C, Ouermi D, et al. HCV prevalence and co-infection with HIV among pregnant women in saint camille medical centre, Ouagadougou. Trop Med Int Health. 2011 Nov; 16(11): 1392-6.

12 Zeba MT, Sanou M, Bisseye C, Kiba A, Nagalo BM, Djigma FW, et al. Characterisation of hepatitis $\mathrm{C}$ virus genotype among blood donors at the regional blood transfusion centre of Ouagadougou, Burkina Faso. Blood Transfus. 2014 Jan;12(Suppl 1):s54-7.

13 Simpore J, Ilboudo D, Samandoulougou A, Guardo P, Castronovo P, Musumeci S. HCV and HIV co-infection in pregnant women attending St. camille medical centre in Ouagadougou (Burkina Faso). J Med Virol. 2005 Feb;75(2):209-12.

14 Smith DB, Bukh J, Kuiken C, Muerhoff AS, Rice CM, Stapleton JT, et al. Expanded classification of hepatitis $\mathrm{C}$ virus into 7 genotypes and 67 subtypes: updated criteria and genotype assignment web resource. Hepatology. 2014 Jan;59(1):318-27.

15 Messina JP, Humphreys I, Flaxman A, Brown A, Cooke GS, Pybus OG, et al. Global distribution and prevalence of hepatitis $\mathrm{C}$ virus genotypes. Hepatology. 2015 Jan;61(1):7787.

16 Simpore J, Granato M, Santarelli R, Nsme RA, Coluzzi M, Pietra V, et al. Prevalence of infection by HHV-8, HIV, HCV and HBV among pregnant women in Burkina Faso. J Clin Virol. 2004;31(31):78-80.

17 Serme AK, Ilboudo PD, Samandoulgou A, Simpore J, Bougouma A, Sombie AR. Portage du virus de l'hépatite $C$ chez les femmes enceintes et transmission mère-enfant à Ouagadougou, Burkina Faso [Prevalence of hepatitis $C$ virus infection in pregnant women and mother-child transmission in Ouagadougou, Burkina Faso]. Bull Soc Pathol Exot. 2006 May;99(2):108-9.

18 Nagalo MB, Sanou M, Bisseye C, Kaboré MI, Nebie YK, Kienou K, et al. Seroprevalence of human immunodeficiency virus, hepatitis $\mathrm{B}$ and $\mathrm{C}$ viruses and syphilis among blood donors in Koudougou (Burkina Faso) in 2009. Blood Transfus. 2011 Oct;9(4):419-24.

19 Moradpour D, Müllhaupt B. 'Hépatite C: épidémiologie, histoire naturelle et diagnostic'. Rev Med Suisse. 2015;1:896-901.

20 Elsheikh RM, Daak AA, Elsheikh MA, Karsany MS, Adam I. Hepatitis B virus and hepatitis $\mathrm{C}$ virus in pregnant Sudanese women. Virol J. 2007;4(1):104-3.

21 Carter W, Connelly S, Struble K. Reinventing HCV treatment: past and future perspectives. J Clin Pharmacol. 2017 Mar;57(3):287-96.

22 Ministère. Plan Stratégique de Lutte Contre les Hépatites virales au Burkina Faso. Burkina Faso: Ministère de la Santé; 2021. Available from: https://www.sante.gov.bf/accueil consulted in 2021 Apr.
23 EASL. EASL recommendations on treatment of hepatitis C: final update of the series. J Hepatol. 2020 Nov;73(5):1170-218.

24 Collenberg E, Ouedraogo T, Ganamé J, Fickenscher H, Kynast-Wolf G, Becher H, et al. Seroprevalence of six different viruses among pregnant women and blood donors in rural and urban Burkina Faso: a comparative analysis. J Med Virol. 2006 May;78(5):683-92.

25 Tao I, Compaoré TR, Diarra B, Djigma F, Zohoncon TM, Assih M, et al. Seroepidemiology of hepatitis B and $\mathrm{C}$ viruses in the general population of burkina faso. Hepat Res Treat. 2014;2014:781843.

26 Dandachi D, Hassan M, Kaseb A, Angelidakis $\mathrm{G}$, Torres HA. Hepatitis C virus-associated hepatocellular carcinoma as a second primary malignancy: exposing an overlooked presentation of liver cancer. J Hepatocell Carcinoma. 2018;5:81-6.

27 Goto K, Roca Suarez AA, Wrensch F, Baumert TF, Lupberger J. Hepatitis C virus and hepatocellular carcinoma: when the host loses its grip. Int J Mol Sci. 2020 Apr 26;21(9):21.

28 El-Serag HB, Rudolph KL. Hepatocellular carcinoma: epidemiology and molecular carcinogenesis. Gastroenterology. 2007;132(7): 2557-76.

29 White T. Hadoop: the definitive guide. O'Reilly Media, Inc.; 2012.

30 Assih M, Ouattara AK, Diarra B, Yonli AT, Compaore TR, Obiri-Yeboah D, et al. Genetic diversity of hepatitis viruses in West-African countries from 1996 to 2018. World J Hepatol. 2018;10(11):807.

31 Candotti D, Temple J, Sarkodie F, Allain JP. Frequent recovery and broad genotype 2 diversity characterize hepatitis $C$ virus infection in Ghana, West Africa. J Virol. 2003 Jul; 77(14):7914-23.

32 Farhood B, Najafi M, Mortezaee K. CD8(+) cytotoxic T lymphocytes in cancer immunotherapy: a review. J Cell Physiol. 2019 Jun; 234(6):8509-21.

33 Vayssières E. Le virus de l'hépatite $\mathrm{C}$ : bilan de 30 années de recherche; 2019. Available from: https: //planet-vieensfr/article/2599/virushepatite-c-bilan-30-annees-recherche.

34 Sakr AA, Dyab WM, Wu K. Theory of polarization-selective coupling and its application to design of planar orthomode transducers. IEEE Trans Antennas Propagation. 2017; 66(2):749-62.

35 Zein NN. Clinical significance of hepatitis C virus genotypes. Clin Microbiol Rev. 2000 Apr;13(2):223-35.

36 Taherkhani R, Farshadpour F. Epidemiology of hepatitis C virus in Iran. World J Gastroenterol. 2015 Oct 14;21(38):10790-810.

37 Zuberi BF, Zuberi FF, Hasan SR, Kumar R, Memon SA, Afsar S. Frequency of acute hepatitis $\mathrm{C}$ after needle stick injury and its treatment outcome. Consultant. 2009;6:02-9. 
38 Al-Jamal M, Al-Qudah A, Al-Shishi KF, AlSarayreh A, Al-Quraan L. Hepatitis C virus $(\mathrm{HCV})$ infection in hemodialysis patients in the south of Jordan. Saudi J Kidney Dis Transpl. 2009;20(3):488.

39 Burstow NJ, Mohamed Z, Gomaa AI, Sonderup MW, Cook NA, Waked I, et al. Hepatitis $\mathrm{C}$ treatment: where are we now? Int J Gen Med. 2017;10:39.

40 Daw MA, Buktir Ali LA, Daw AM, Sifennasr NEM, Dau AA, Agnan MM, et al. The geographic variation and spatiotemporal distribution of hepatitis $C$ virus infection in Libya: 2007-2016. BMC Infect Dis. 2018 Nov 22; 18(1):594.
41 Pagliaccetti NE, Chu EN, Bolen CR, Kleinstein SH, Robek MD. Lambda and alpha interferons inhibit hepatitis $\mathrm{B}$ virus replication through a common molecular mechanism but with different in vivo activities. Virology. 2010;401(2):197-206.

42 Grebely J, Robaeys G, Bruggmann P, Aghemo A, Backmund M, Bruneau J, et al. Recommendations for the management of hepatitis $\mathrm{C}$ virus infection among people who inject drugs. Int J Drug Policy. 2015 Oct;26(10):1028-38.

43 Chute DF, Chung RT, Sise ME. Direct-acting antiviral therapy for hepatitis $\mathrm{C}$ virus infection in the kidney transplant recipient. Kidney Int. 2018;93(3):560-7.
44 Chiu H-C, Chiu Y-C, Yang E-H, Chang T-T, Chien S-C, Wu I-C, et al. Effectiveness and safety of ledipasvir/sofosbuvir for genotype 2 chronic hepatitis $\mathrm{C}$ infection: real-world experience from Taiwan. J Formos Med Assoc. 2021 Mar;120(3):983-90.

45 Balistreri WF, Murray KF, Rosenthal P, Bansal S, Lin CH, Kersey K, et al. The safety and effectiveness of ledipasvir-sofosbuvir in adolescents 12-17 years old with hepatitis C virus genotype 1 infection. Hepatology. 2017 Aug;66(2):371-8.

46 Haley DF, Edmonds A, Ramirez C, French AL, Tien P, Thio CL, et al. Direct-acting antiviral hepatitis $C$ treatment cascade and barriers to treatment initiation among us men and women with and without HIV. J Infect Dis. 2021 Jun 15;223(12):2136-44. 